\title{
Alternative Worldviews and the Utilization of Conventional and Complementary Medicine*
}

\author{
Kristen D. Hildreth, Medina County Health Department \\ Cheryl Elman, The University of Akron
}

\begin{abstract}
We use the Midlife in the United States (MIDUS) database and an expanded Anderson model that incorporates health beliefs, including sacred worldviews as predisposing factors, to explore conventional and complementary and alternative medical (CAM) service use. Findings are that health care need, especially the number of chronic conditions is positively associated with both conventional and CAM services use. However, net of need, health beliefs and sacred worldviews differentiate CAM users versus nonusers or the number of different CAM practices that are used. Higher self-rated spirituality is associated with being a CAM user and, if a user, with adopting a wider range of practices. Individuals with higher self-rated religiosity are not more or less likely to be CAM users but adopt significantly fewer techniques, if users. We discuss the attraction to very different faces of health care, on the basis of religiosity, spirituality, and other health beliefs, with implications for policymakers and care providers.
\end{abstract}

There has been dramatic growth in the use of complementary and alternative medicine (CAM) in the United States over the last decade (Eisenberg et al. 1998; NCCAM 2000), although we still seek to understand what motivates its use. ${ }^{1}$ This knowledge gap partly reflects a lack of nationally representative studies about CAM use (Ernst 2000; Ruggie 2004). ${ }^{2}$ But CAM users are also difficult to characterize because they resemble conventional health care users: both user groups have somewhat similar demographic and socioeconomic attributes, as well as high rates of chronic health problems (Eisenberg et al. 1998; McFarland et al. 2002; Ni, Simile, and Hardy 2002; Rafferty et al. 2002; Ruggie 2004). Most adults use CAM as an "add-on" and not as a substitute for conventional care (Druss and Rosenheck 1999; Eisenberg et al. 1998; McFarland et al. 2002).

However, health beliefs, including religious and spiritual worldviews, differentiate CAM from conventional medical care users. Although few nationally representative studies have examined these effects, international and smaller scale studies consistently find that health-related beliefs significantly shape CAM use. ${ }^{3}$ We use a nationally representative dataset, Midlife in the United States (MIDUS; Brim et al. 2000) and a Behavioral Model of Health Services Use (Andersen 1995) to explore whether individual difference factors such as 
openness to new things, and health beliefs, especially religious and spiritual beliefs, influence CAM or conventional medical care utilization.

\section{Review of the Literature}

\section{Health Services Use}

The Andersen model has long been the model of choice for those who study the use of medical care services (Andersen 1995; Andersen, Kravis, and Andersen 1975). The original model conditions conventional medical care use on three sets of factors: the need for health care, the predisposition to use health care, and mechanisms that enable health care utilization, such as health insurance. The presence of all three components results in realized access to care.

The need for care is one of the most robust predictors of conventional medical care use (Andersen et al. 1975; Green and Pope 1999; Noelker et al. 1998; Rew 1998) and reflects poor health or concern about health. Need is generally operationalized by objective measures, such as the presence of one or more medical condition(s), symptoms, or specific diseases. Need is often also operationalized by subjective measures, such as self-perceived health. Predisposing factors, such as older age, being female, white, and having higher education, encourage individuals to seek conventional care. Andersen's recent reconceptualization of the model elevates the role of social support in the study of access to care: social support can promote and reinforce members' careseeking behaviors (Andersen 1995) and increase individuals' positive assessments about the efficacy of conventional care or about the ability of physicians to treat disease (Green and Pope 1999; Noelker et al. 1998; Rew 1998). Finally, individual- and community-level enabling resources, such as the income-topurchase care, health insurance coverage, and geographic accessibility to health providers increase conventional health care use (Gelberg et al. 1997; Noelker et al. 1998; Rew 1998).

The Anderson model has recently been used to study CAM utilization (Astin 1998; Kelner and Wellman 1997; Sirois and Gick 2002); even studies that do not explicitly apply the model examine CAM use in light of health needs, demographic/predisposing, and economic/enabling factors. Similar to conventional care, need is a strong predictor of CAM use (Astin 1998; Astin et al. 2000; Bair et al. 2002; Cherniack, Senzel, and Pan 2001; Druss and Rosenheck 1999; Ni et al. 2002; Sirois and Gick 2002; Wolsko et al. 2002). Similarly, sociodemographic predisposing factors, such as being female, white, and having a higher education are associated with greater CAM use (Bair et al. 2002; Barnes et al. 2004; Berstein and Shuval 1997; Cherniack et al. 2001; Eisenberg et al. 1998; Ernst 2000; Wolsko et al. 2000, 2002). Social support has only rarely been examined in CAM research (see Wellman [2003] on networks 
and diffusion of CAM). Because information about alternative providers and treatments is difficult to obtain (Ruggie 2004) and because lay referrals promote CAM use (Caspi, Koithan, and Criddle 2004; Kelner and Wellman 1997; Sharma 1992; Wellman 2003) social support should positively influence the use of alternative treatment.

Higher income, an enabling factor, increases CAM as much as it increases conventional medical care use (Bair et al. 2002; Berstein and Shuval 1997; Eisenberg et al. 1998; Ernst 2000; Kelner and Wellman 1997). There is less consistency in findings across studies about the role of insurance in CAM use. Wolsko et al. (2002) found that insured adults are more likely to use CAM, but Druss and Rosenheck (1999), whose national sample included poorer and non-English speaking respondents, found that the uninsured used more CAM. Insurance was not significant after controls in $\mathrm{Ni}$ et al. (2002). In summary, explorations of CAM use echo earlier findings about conventional medical care use: CAM use reflects need, the predisposition to seek care, and the ability to purchase care.

Early studies focused on the "alternative" aspect of CAM use but most scholars now agree that conventional care utilization is itself associated with CAM use; only a small proportion of U.S. adults (about 9\%) make a majority of the CAM visits (about 75\%), and they also tend to be high users of conventional care (Wolsko et al. 2002). Moreover, a significant proportion - perhaps a majority - of conventional care providers recommend CAM to their patients (Astin 1998; Rafferty et al. 2002), although most patients do not discuss CAM therapies with their physicians (Druss and Rosenheck 1999; Eisenberg et al. 1998). Unfortunately, most studies are cross-sectional and so research design has not allowed the study of causal mechanisms that precipitate different types of service use. There is evidence that individuals dissatisfied with conventional medicine are more likely to use CAM (Astin 1998; Astin et al. 2000; McGregor and Peay 1996; Sirois and Gick 2002). But satisfied users of conventional medicine adopt CAM and most CAM users seek conventional care. Only a small proportion of CAM users avoid conventional care (Astin 1998; Barnes et al. 2004; Ni et al. 2002). ${ }^{4}$

\section{CAM Use and Predisposing Health Beliefs}

Andersen (1995) recently proposed that the behavioral model should place greater emphasis on health beliefs and their impacts on health care utilization. However, such a wide range of individual difference factors, health beliefs, and worldviews differentiate CAM users and their choices of practice that CAM users have been likened to an array of "alternative patients" (Caspi et al. 2004; Furnham and Vincent 2003; Sirois and Gick 2002). Yet three key domains appear to be associated with CAM use (Ruggie 2004): a personal orientation 
toward holistic, sacred worldviews (Astin 1998; Goldstein 1999; Kelner and Wellman 1997; Williams 1998); a sense of health control, agency, and "empowerment" (Astin 1998; Furnham and Beard 1995; Ruggie 2004; Sirois and Gick 2002); and personal characteristics of openness and creativity (Astin 1998; McGregor and Peay 1996; Sirois and Gick 2002). These domains are not mutually exclusive as some, none, or all may be present in a given individual. There is debate about the association of these domains with CAM use, and so we examine their relation to CAM and conventional care use in this study.

Some individuals may view their state of health as a reflection of religious or spiritual, as well as physical well-being (religious and spiritual holism) (Astin 1998; Kelner and Wellman 1997; Pawluch, Cain, and Gillett 1994). Religious and spiritual worldviews appear to overlap in what is termed the sacred: when persons interpret experience in reference to the transcendent, sacred, or divine (George et al. 2000; Zinnbauer, Pargament, and Scott 1999). There is also a positive relationship between religious and spiritual worldviews and general health, life satisfaction, and quality of life (Dull and Skokan 1995; Levin and Chatters 1998; Poloma and Pendleton 1989, 1990). Until the 1970s, scholarship viewed most elements of religious belief in this broader light so that spirituality was not often differentiated from the religiousness construct (Zinnbauer et al. 1999).

But even though "religiosity" and "spirituality" overlap in sacred experience and predispose to CAM use (Astin 1998; Goldstein 1999; Kelner and Wellman 1997; Ruggie 2004; Sutherland, Poloma, and Pendleton 2003) they are not identical orientations. Perhaps a key difference is that religiosity implicates a system of beliefs, relationships, and behaviors that influence daily life events by incorporating the support and validation of institutional and often hierarchical communities (Chatters 2000; Dull and Skokan 1995; George et al. 2000; Zinnbauer et al. 1999). In contrast, spirituality is more a personal quest, generally less embedded in institutional forms and collective activity (George et al. 2000). A similar distinction is made by Wuthnow (1998); also see Wink and Dillon 2003): he likens religiosity to "dwelling" in that individuals come to inhabit an institutional and traditional "space" - and often a specific geographical space as well-potentially linked to the sacred. "Dwelling" does not preclude transcendent or charismatic experience, but such experiences may then be viewed in light "of the book," or rooted in liturgy and other elements of established belief that promote a stable religious identity.

Wuthnow (1998) suggests that spirituality, in contrast, is "seeking" the sacred in uniquely personal and transformative quests (also see Sutherland et al. 2003). Labels or fixed identities, whether of the seeker, or that which is sought, are less important in the spiritual odyssey. Although difficult to distinguish 
empirically, ${ }^{5}$ both religious and spiritual attitudes are important to consider in CAM use studies because each appears to be a distinct predictor of health behaviors and treatment choice options (Dull and Skokan 1995). Religiosity ("influence of God") is associated with less CAM use (Furnham and Beard 1995 ) and having "no religion" is associated with greater CAM use (Kelner and Wellman 1997). Also, a spiritual orientation ("holism" and "transformative experience that leads to seeing the world differently") is associated with greater CAM use (Astin 1998; Kelner and Wellman 1997).

Why might spirituality promote, and religiosity discourage greater alternative health services use? Goldstein (1999) provides insight by noting that conventional health care became hospital-centered after the turn of the twentieth century - in a manner of "dwelling." Conventional medicine is also "of the book," in that treatment protocols, once established, tended to be repeated, becoming orthodoxy and institutionalized. Conventional care has also been rooted in hierarchical social relations that fix identities, with specialist physicians at the top and careseekers at the bottom of the hierarchy. In contrast, CAM is notable for its holism (mind-body-spirit interdependence in health) which precludes orthodox, rote approaches to care. Finally, Goldstein (1999) notes that CAM tends to promote the secularization of some religious practices, such as meditation or energy healing, and to spiritualize other practices, such as massage, although such conversions may be a cause or a consequence of CAM's growing universal appeal. But the secularization of the divine and the elevation of the secular that is inherent in CAM use may alienate those individuals with a religious, and attract those individuals of a spiritual bent.

Other health beliefs are associated with CAM use. One health belief orientation, health effort, may lead to CAM practices, because such practices require commitment over the immediate to long term (e.g., training in biofeedback, learning the special preparation of food, long-term meditation, etc.) as well as health awareness. But this type of commitment or health effort may also be present in the context of conventional treatment as well (i.e., compliance with conventional treatment regimens).

Another health belief, of health control, has been operationalized in numerous ways, including as locus of control related to health; the desire for autonomy and decision-making control; self-education; and the self-monitoring of health (Furnham and Beard 1995; Kelner and Wellman 1997; Ruggie 2004; see Sirois and Gick 2002 for discussion of health control issues). However, individuals with a greater motivation for personal health control may be less dedicated to CAM as a philosophy of treatment or lifestyle, and be more concerned about decision-making input and autonomy (Furnham and Vincent 2003). For example, in a small exploratory analysis Astin (1998) finds that decision-making control was associated with CAM use among CAM-only users 
who also were dissatisfied with conventional care. However, other studies find that a greater desire for decision-making control does not predict CAM use (Astin 1998; Sirois and Gick 2002) and that exerting health control by seeking health information versus avoiding information does not affect CAM use (Furnham and Beard 1995).

Another individual difference factor associated with CAM use that can be differentiated as a predisposing factor is openness to new things or ideas. Adopters of nonconventional medicine appear to be predisposed to personal openness (Sirois and Gick 2000) and creativity, or the desire to try novel activities, including alternative health-related practices (Astin 1998).

\section{Hypotheses}

Based on the health services use literature and using Andersen's most recent model (1995) we expect to find that the traditional, predisposing factors identified (being female, older, white, having a higher education) will result in a greater use of regular medical services and CAM. We also expect to find that enabling factors (higher income, having insurance, and having a usual place for medical care) and need factors (the number of chronic conditions, impairment in instrumental activities of daily living or IADLs; impairment in basic activities of daily living or BADLs; and health status 10 years previous) will result in a greater utilization of regular services and CAM, although health insurance may be less important for CAM use. Beyond this, expectations are:

H1: Self-reported religiosity is positively associated with conventional health care service use and inversely related with CAM use.

H2: Self-reported spirituality does not significantly increase or decrease conventional care use but is positively associated with CAM use.

H3: Health effort is positively associated with conventional and CAM use. Health control is inversely associated with conventional care use, positively associated with CAM use.

H4: Greater personal openness is not associated with conventional use but is positively associated with CAM use.

H5: Conventional service use is positively associated with CAM use.

H6: Social support is positively associated with conventional care and CAM use.

\section{Data, Model, and Methods}

\section{Data}

The hypotheses above are tested in a sample taken from the National Survey of Midlife Development in the United States (MIDUS), which was 
sponsored by the MacArthur Foundation. The survey was conducted in 1995 and is a nationally representative sample of noninstitutionalized, English-speaking adults between 25 to 74 years of age, with over sampling of men and older respondents. Representativeness of the sample has been increased by the construction of sample weights (included with the data) that adjust for differences in the likelihood of selection and differential response rates (Brim et al. 2003). Respondents were initially contacted by phone using a random-digit-dialing technique; follow-up questions were fielded by mail questionnaires. The main survey $(N=3032)$ response rate is estimated by MIDUS researchers to be 60.8 percent $(70.0 \%$ for the telephone interview, 86.8 percent for the main questionnaire, or $0.70 \times 868=.608)$.

Our study sample is limited to respondents who completed both the telephone survey and the questionnaire, and are between the ages of 31 to 64 in $1995(n=1672)$. We limit the sample to those under the age of 65 because medical access to providers and utilization is, because of national policy, significantly different for individuals over and under the age of 65 . We constrain the sample at the other end of the age range (31 years) because there is strong evidence that, whereas the level of "religiosity" appears to remain stable across the life course, "spirituality" emerges as a midlife phenomenon (McFadden 1996; Wink and Dillon 2003). ${ }^{6}$ All of the analyzed data in the tables presented are weighted by the final sample weights that are provided with the MIDUS data.

\section{Dependent Variables}

Several dependent variables are used that measure health services use, conventional and alternative. The first dependent variable, "Conventional Health Service Visits," is a count, the number of times the respondent saw "a doctor, hospital, or clinic for a routine visit or gynecological exam"; saw "a dentist or optician for a routine checkup or exam"; saw "a doctor, emergency room, or clinic for urgent care treatment" (e.g., because of new symptoms, an accident, or something similar); and/or saw "a doctor, hospital, clinic, orthodontist, or ophthalmologist for scheduled treatment or surgery." The first two categories are routine and prevention oriented, the last two are treatment oriented.

A second dependent variable, "Any CAM use," is a dichotomous variable with a value of 1 if any type of the following 15 alternative services were used in the past year, based on the five domains of CAM recognized by the National Institutes of Health $^{7}$ : acupuncture, homeopathy, biofeedback, hypnosis, imagery, meditation for healing purposes, spiritual practices for healing, spiritual healing by others, herbal therapy, high dose vitamins, special diets, chiropractic, massage therapy, exercise/movement therapy, and energy healing. A third dependent variable, "Number of CAM techniques used" in last year 
sums the types of CAM used for those who use any CAM, based on these 15 services.

\section{Independent Variables}

Predisposing factors, as traditionally modeled, include demographic characteristics, socioeconomic status, and social support. They are represented in this study by variables that measure gender, age, race, education level, and marital/cohabitation status. Gender is indicated by a dummy variable, "Female" $(=1)$. "Age" is a continuous variable from 31 to 64 years, ages of the sample in the survey year. Race is indicated by a dummy variable, "White" $(=1$, Others $=0$ ). Education level is represented by a series of dummy variables: "Some grade school" (reference category); "GED or high school"; "Some college"; and "College degree or greater." Level of education is a robust and stable predictor of health and the best indicator to use when measuring the relationship between socioeconomic status and health (Kitigawa and Hauser 1973). It is correlated with income and occupation, but because educational attainment generally emerges early in life and shapes the basic health behaviors and attitudes formed early in life, it is the main pathway through which socioeconomic status influences health status (Ross and Wu 1995; Wray et al. 1998). A dummy variable "Marital/cohabiting union" is a robust measure of family social support and is equal to one $(=1)$ if the respondent is married or cohabiting.

Health beliefs predispose individuals to use-or to not use-health care services. We examine several types of health beliefs or worldviews. The representative MIDUS provides extraordinary breadth of information about health care utilization and individual psychological and social attributes, but was not gathered for the purpose of this study and so has, unfortunately, less depth in this area than might be wished. Only four questions were asked about sacred worldviews, and health beliefs such as health control, health effort, and openness are tapped only as single questions, limiting our ability to form scales (see Sirois and Gick 2002 for discussion of health control scales). Also, the generally cross-sectional design hides process, dynamism, and the true directions of the relationships between health services, health beliefs, health practices, and health status. We do not intend to imply causal relationships.

The first domain examined pertains to religious and spiritual worldviews. Religious orientation is represented in the data set by two questions that ascertain the degree of religiosity: "How religious are you?" (reverse coded so that range $1=$ Not at all, $4=$ Very); and the importance of religion "How important is religion in your life?" (reverse coded so that range $1=$ Not at all, $4=$ Very). The responses for the two variables are summed to form "Self-rated religiosity," range 1-8. Similarly, spiritual orientation is represented in the data set by two 
questions that ascertain the degree of spirituality: "How spiritual are you?" (reverse coded, range $1=$ Not at all, $4=$ Very); and the importance of being spiritual "How important is spirituality in your life?" (reverse coded, range $1=$ Not at all, $4=$ Very). The responses for these two variables are summed to form "Self-rated spirituality," range 1-8. The four questions are sequential in the survey, and respondents were required to differentiate between these domains, although the criteria by which they self-classify were not ascertained. ${ }^{8}$ The first-order correlation of the two constructs is .58. Regression diagnostics (variance inflation factor and tolerance tests) reveal no sign of collinearity when both constructs are included in equations.

A second domain of health beliefs is personal responsibility for health, indicated by two ordinal variables treated as continuous variables, "Health control"- "How would you rate the amount of control you have over your health these days?" (range $0=$ None, $10=\mathrm{A}$ lot); and "Health effort"- "How much thought and effort do you put into your health these days?" (range $0=$ None, $10=$ A lot). Their first-order correlation is .29. Religiosity has a first-order correlation with health control of $.04, p<.075$ and with health effort of .18 , $p<.0001$. Spirituality has a first-order correlation with health control of .08 , $p<.001$ and with health effort of .17, $p<.0001$. A final domain is one of openness or orientation toward involvement in new things. This is indicated by a single variable, "Openness," as defined through the question "How open are you to new experiences?" (range $1=$ Not very, $4=$ Very much). Openness has a first-order correlation with spirituality of $.13, p<.0001$ and with religiosity of $-.03, p<.10$ (n.s.). Openness has a first-order correlation with health control of $.17, p<.0001$ and with health effort of $.14, p<.0001$. Unfortunately, health effort, health control, and openness are complex phenomena and the single measures of them included in the database do not allow the sophisticated treatment that these concepts require. Ideally, questioning would allow scales and instruments to be formed and so better identify these domains. Future research with better indicators will be necessary to advance our knowledge about health beliefs and CAM use.

Enabling factors are represented by variables that include individual and community resources, such as income, insurance, and an available place to obtain medical care. Personal income is recorded in the MIDUS data as 36 categories; each category is recoded to be the midpoint dollar amount; the 36 category recoded variable is logged. Income is imputed for 12 individuals with missing values as follows: a person is assigned the mean income for occupation by gender (as ascertained by three-digit occupational code) based on own occupation (current, or if not currently employed, previous occupation) and gender. In addition to an objective indicator of income, we examine "Perceived financial status"- "How would you rate your financial situation these days" (self-rated, 
ranging from $0=$ worst possible financial situation and $10=$ best possible financial situation). "Health insurance" is a dichotomous variable determined by whether a respondent has any of a number of types of insurance coverage (e.g., employer-based, spouse, government). " "Availability of health services" is ascertained by whether respondents have an accustomed place for medical care $($ Yes $=1)$.

Need precipitates the use of conventional medical care, but also promotes alternative care, although the latter may be used prior to the emergence of poor health (McGregor and Peay 1996). Variables that measure need include "Number of chronic conditions," the number of intermediate-level functional disabilities or "IADLs," including difficulty climbing stairs, carrying groceries, bending or kneeling, walking more than several blocks, more than moderate activity; and the number of severe disabilities pertaining to basic needs, "BADLs," such as difficulty bathing or dressing. We also control for retrospective, self-perceived health status, 10 years prior to the survey- "Looking back 10 years ago, how would you rate your health at that time?" (range $0=$ worst, $10=$ best $)$.

\section{Methods}

A negative binomial regression, a special case of a generalized linear model, is used to estimate the effects of predisposing (traditional indicators and health belief ideologies), enabling, and need factors on the count dependent variable "Conventional health service visits." The count variable's distribution is skewed, due to outlying values ( 26 persons, about $1 \%$ of the sample had $>25$ visits a year) and numerous reports of zero visits (about $15 \%$ of the sample). Both Poisson and negative binomial regression models can accommodate such a dependent variable; both constrain the predicted values to be positive (protect against finding theoretically impossible negative utilization). However, Poisson models assume that the mean for each observation is equal to its variance; a test of this assumption, using the SAS GENMOD procedure, indicates the presence of overdispersion (e.g., that the Poisson distributional assumption does not hold). This finding recommends the use of negative binomial regression methods.

CAM utilization is estimated in two steps: a logistic equation first predicts the dichotomy, "Any CAM use." In a second step, linear regression is used to estimate the summed types of CAM treatments used in the previous year, if any were used $(>0)$. Ordinary least square (OLS) regression diagnostics found significant heteroscedasticity, as identified by White's test. Therefore standard errors of the second stage equation (Table 4) are adjusted by White's (1980) method using weighted linear regression (GLS) in SAS PROC model. 


\section{Results}

Table 1 presents the weighted means and standard deviations of the continuous variables and proportions of the dichotomous variables used in the study. About 53 percent of the full sample has used at least one type of CAM in the last year; the average number used by those who have used at least one type of CAM is 2.07. A comparison of CAM users and nonusers finds users to be significantly younger, female, white, and more educated. They are less likely to be married or in a domestic relationship. CAM users have a higher income and are more likely to have health insurance and a usual source of care than nonusers. CAM users versus nonusers have twice the number of chronic conditions and report poorer self-perceived health status in the 10 years prior to the interview. With the exception of health control, CAM users score higher than nonusers across the health belief domains.

\section{Conventional Utilization}

Table 2 presents negative binomial regression equation estimates of conventional medical service use. The first model includes basic predisposing, enabling, and need variables. Some college versus no high school diploma (all educational categories are compared to not having a high school degree, the reference category) is the only predisposing variable significantly associated with service use and increased use. Enabling factors, such as health insurance and a usual source of care, more than predisposing factors, predict conventional service use. Income is not significant in this model, but individuals who believe that they are better off financially, as indicated by perceived financial status, use fewer services. Need, indicated by chronic conditions and IADL dependencies promotes conventional use. Individuals who report a better prior health status 10 years before the interview (based on recall), report higher current use. Their visits may be preventive, informational, diagnostic, or treatment-focused or, more likely in today's medical practice, a combination of services. Severe functional impairment is not associated with utilization; unfortunately, measures of alternative types of routine medical care that disabled persons use, such as home health care visits, are not available in the data. Against expectations, social support is not a significant predictor of conventional service use.

The second model adds health belief indicators. As expected, spirituality, and, against expectations, religiosity, do not predict the level of conventional service use. The two health control-related indicators are significant in the equation, and, as expected, have opposite effects. A greater sense of health control is associated with significantly less conventional care service use. These individuals may avoid conventional medical care (Astin 1998) or seek medical care as a last resort. In contrast, greater health effort is associated with 
Table 1

Descriptive Statistics

\begin{tabular}{|c|c|c|c|c|c|c|}
\hline \multirow[b]{2}{*}{ Variable (range, if continuous) } & \multirow[b]{2}{*}{$\begin{array}{c}\text { Sample } \\
\text { Mean }\end{array}$} & \multirow[b]{2}{*}{ S.D. } & \multicolumn{2}{|c|}{$\begin{array}{l}\text { Complementary } \\
\text { and alternative } \\
\text { medicine } \\
\text { (CAM) users }\end{array}$} & \multirow[b]{2}{*}{$\begin{array}{c}\text { Nonusers } \\
\text { Mean }\end{array}$} & \multirow[b]{2}{*}{ S.D. } \\
\hline & & & Mean & S.D. & & \\
\hline \multicolumn{7}{|l|}{ Predisposing factors (traditional measures) } \\
\hline Age $(31-64$ years $)$ & 44.94 & 9.34 & $45.02 * *$ & 9.09 & 46.84 & 9.64 \\
\hline Female (versus male) & .57 & - & $.64 * *$ & - & .49 & - \\
\hline White (versus non-white) & .89 & - & $.91 * *$ & - & .87 & - \\
\hline High school diploma & .40 & - & $.37 * *$ & - & .42 & - \\
\hline Some college & .26 & - & $.28 * *$ & - & .23 & - \\
\hline College degree (versus no high school diploma) & .24 & - & $.28 * *$ & - & .20 & - \\
\hline In marital/cohabiting union & .77 & - & $.76^{* *}$ & - & .79 & - \\
\hline \multicolumn{7}{|l|}{ Enabling factors } \\
\hline Income (unlogged, $\$ 0-\$ 125,000$ ) & 26,360 & 24,769 & $25,607 * *$ & 23,328 & 25,322 & 26,415 \\
\hline Perceived finances $(0-10)$ & 5.93 & 2.17 & $5.85^{* *}$ & 2.12 & 5.86 & 2.22 \\
\hline Health insurance & .90 & - & $.90 * *$ & - & .87 & - \\
\hline Usual source of care & .80 & - & $.83 * *$ & - & .75 & - \\
\hline \multicolumn{7}{|l|}{ Need factors } \\
\hline Number of chronic conditions (unlogged, 0-27) & 2.58 & 2.71 & $3.09 * *$ & 3.27 & 1.83 & 2.50 \\
\hline IADLs-intermediate limitations (1-4) & 1.58 & .77 & $1.66^{* *}$ & .78 & 1.43 & .74 \\
\hline BADLs-severe limitations $(1-4)$ & 1.17 & .52 & $1.17 * *$ & .47 & 1.14 & .58 \\
\hline Health status 10 years earlier ( 0 lowest -10 highest) & 8.21 & 1.71 & $8.04 * *$ & 1.69 & 8.27 & 1.72 \\
\hline
\end{tabular}




\begin{tabular}{|c|c|c|c|c|c|c|}
\hline \multirow[b]{2}{*}{ Variable (range, if continuous) } & \multirow[b]{2}{*}{$\begin{array}{l}\text { Sample } \\
\text { Mean }\end{array}$} & \multirow[b]{2}{*}{ S.D. } & \multicolumn{2}{|c|}{$\begin{array}{l}\text { Complementary } \\
\text { and alternative } \\
\text { medicine } \\
\text { (CAM) users }\end{array}$} & \multirow[b]{2}{*}{$\begin{array}{c}\text { Nonusers } \\
\text { Mean }\end{array}$} & \multirow[b]{2}{*}{ S.D. } \\
\hline & & & Mean & S.D. & & \\
\hline \multicolumn{7}{|l|}{ Health beliefs and individual factors } \\
\hline Control over health $(0-10)$ & 7.63 & 1.87 & $7.52 * *$ & 1.89 & 7.63 & 1.85 \\
\hline Health effort $(0-10)$ & 7.14 & 2.02 & $7.23 * *$ & 1.90 & 6.89 & 2.15 \\
\hline Religiosity (1-8) & 5.88 & 1.61 & $6.06 * *$ & 1.64 & 5.58 & 1.54 \\
\hline Spirituality (1-8) & 6.12 & 1.52 & $6.46^{* *}$ & 1.46 & 5.75 & 1.51 \\
\hline Openness $(1-4)$ & 3.00 & .52 & $3.01 * *$ & .51 & 2.94 & .53 \\
\hline \multicolumn{7}{|l|}{ Utilization of care and health outcomes } \\
\hline Number regular visits (range $0-112$ ) & 2.98 & 4.04 & $3.80 * *$ & 6.12 & 2.38 & 3.94 \\
\hline Any complementary/alternative medicine & .53 & - & - & - & - & - \\
\hline Whole sample, number of CAM techniques used $(0-15)$ & 1.27 & 1.52 & - & - & - & - \\
\hline If CAM ever used, number of techniques used $(1-15)$ & - & - & 2.07 & 1.67 & - & - \\
\hline$n$ & 1672 & & 920 & & 752 & \\
\hline
\end{tabular}

${ }^{a}$ Significant differences based on $t$-tests, weighted by Midlife in the United States (MIDUS) final weight. $* * p<.001$.

S.D. $=$ standard deviation; IADLs $=$ instrumental activities of daily living; BADLs $=$ basic activities of daily living. 
Table 2

Negative Binomial Regression

Number of physician visits

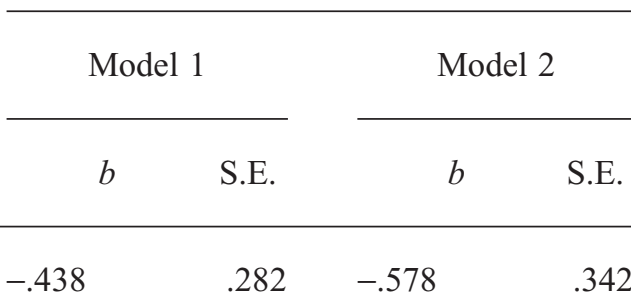

Intercept

Predisposing factors (traditional measures)

Age (years)

Female

White

High school diploma

Some college

College degree or more

Marital/cohabiting union

Enabling factors

Income

Perceived finances

Health insurance

Usual source of care

Need factors

Number of chronic conditions

IADLs

BADLs

Health status 10 years earlier

.004

.059

$-.116$

.197

$.273 *$

.186

$-.082$

.002
$-.042 * *$
$.342 * * *$
$.278 * * *$

.003

.057

.109

.108

.108

.111

.062

.005

.014

.103

.073

$\begin{array}{ll}.274 * * * & .021 \\ .240 * * * & .052 \\ .043 & .078 \\ .047 * * & .016\end{array}$

Health beliefs and individual factors

Control over health

Health effort

Religiosity

$\begin{array}{llcl}- & - & -.066^{* * *} & .017 \\ - & - & .074 * * * & .014 \\ - & - & -.025 & .021 \\ - & - & .040 & .022 \\ - & - & .046 & .056 \\ .819 & .041 & .790 & .040\end{array}$

Openness

Dispersion parameter
.004

.005

$-.041 * *$

$.392 * * *$

.014

$.265 * * *$

.104

.073

.108

.112

.062 
Table 2

(continued)

\begin{tabular}{|c|c|c|}
\hline & \multicolumn{2}{|c|}{ Number of physician visits } \\
\hline & Model 1 & Model 2 \\
\hline & S.E. & S.E. \\
\hline$n$ & 1672 & 1672 \\
\hline df & 1656 & 1651 \\
\hline Log likelihood & 3252.53 & 3272.48 \\
\hline Deviance & 1729.8 & 1725.99 \\
\hline Deviance/df & 1.04 & 1.04 \\
\hline $\begin{array}{l}* p<.05 ; * * p< \\
\text { IADLs }=\text { instru } \\
\text { daily living. }\end{array}$ & ly living; BAL & ic activities of \\
\hline
\end{tabular}

increased utilization. Model fit is assessed by the deviance score divided by the degrees of freedom; both models have adequate fit to the data as shown by a value around 1 .

\section{CAM Service Use}

Table 3 presents the results of logistic regression of the dichotomous indicator, "Any CAM use," on the conventional predisposing, enabling, and need variables (Model 1); on these same variables plus indicators of health beliefs (Model 2); and on all the preceding variables plus the extent of use of conventional services (Model 3).

The results in Model 1 are consistent with most prior studies about CAM use. Predisposing factors such as being female, white, and having a high school degree or more (versus the reference category) is associated with CAM use, as are current health problems, except for severe functional disability. Individuals who report better (self-rated) health status 10 years ago have a lower odds of CAM use; alternatively, reporting poorer past health status is associated with an increased odds of CAM use. However, none of the enabling factors that encourage conventional use predict "Any CAM use." ${ }^{10}$ Health insurance does 
Table 3

Logistic Regression: Utilization of Any Complementary or Alternative Health Service

\begin{tabular}{|c|c|c|c|c|c|c|c|c|c|}
\hline & \multicolumn{3}{|c|}{ Model 1} & \multicolumn{3}{|c|}{ Model 2} & \multicolumn{3}{|c|}{ Model 3} \\
\hline & $b$ & S.E. & OR & $b$ & S.E. & OR & $b$ & S.E. & OR \\
\hline Intercept & -.521 & .520 & & $-2.354 * * *$ & .668 & & $-2.160 * *$ & 682 & \\
\hline \multicolumn{10}{|c|}{ Predisposing factors (traditional measures) } \\
\hline Age & -.011 & .006 & .99 & $-.016^{* *}$ & .006 & .98 & $-.016^{*}$ & .006 & .98 \\
\hline Female & $.556 * * *$ & .113 & 1.75 & $.438 * * *$ & .117 & 1.55 & $.390 * *$ & .118 & 1.48 \\
\hline White & $.502 * *$ & .177 & 1.65 & $.798^{* * *}$ & .186 & 2.22 & $.851 * * *$ & .187 & 2.34 \\
\hline High school diploma & $.633 * * *$ & .192 & 1.88 & $.545^{* *}$ & .197 & 1.73 & $.541 * *$ & .198 & 1.72 \\
\hline Some college & $.956 * * *$ & .203 & 2.60 & $.866 * * *$ & .210 & 2.38 & $.830 * * *$ & .210 & 2.29 \\
\hline College degree or more & $1.269 * * *$ & .209 & 3.56 & $1.171 * * *$ & .218 & 3.23 & $1.150 * * *$ & .218 & 3.16 \\
\hline Marital/cohabiting union & -0.120 & .132 & .89 & -.094 & .137 & .91 & .099 & .138 & .91 \\
\hline \multicolumn{10}{|l|}{ Enabling factors } \\
\hline Income & .002 & .009 & 1.00 & .006 & .010 & 1.01 & .006 & .010 & 1.01 \\
\hline Perceived finances & .005 & .027 & 1.01 & .004 & .028 & 1.01 & .007 & .028 & 1.01 \\
\hline Health insurance & -.023 & .185 & 1.00 & -.024 & .191 & .98 & -.111 & .194 & .90 \\
\hline Usual source of care & .137 & .138 & 1.15 & .087 & .143 & 1.09 & .021 & .145 & 1.02 \\
\hline \multicolumn{10}{|l|}{ Need factors } \\
\hline Number of chronic conditions & $.262 * * *$ & .038 & 1.30 & $.273 * * *$ & .040 & 1.31 & $.238 * * *$ & .041 & 1.29 \\
\hline IADLs & $.441 * * *$ & .111 & 1.55 & $.477 * * *$ & .116 & 1.61 & $.429 * * *$ & .118 & 1.54 \\
\hline
\end{tabular}


Table 3

(continued)

\begin{tabular}{|c|c|c|c|c|c|c|c|c|c|}
\hline & \multicolumn{3}{|c|}{ Model 1} & \multicolumn{3}{|c|}{ Model 2} & \multicolumn{3}{|c|}{ Model 3} \\
\hline & $b$ & S.E. & OR & $b$ & S.E. & OR & $b$ & S.E. & OR \\
\hline BADLs & $-.472 * *$ & .153 & .62 & $-.523 * *$ & .160 & .59 & $-.498 * *$ & .162 & .61 \\
\hline Health status 10 years earlier & $-.084 * *$ & .032 & .92 & $-.087 * *$ & .033 & .92 & $-.088 * *$ & .034 & .92 \\
\hline \multicolumn{10}{|c|}{ Health beliefs and individual factors } \\
\hline Control over health & - & - & - & -.019 & .034 & .98 & -.012 & .034 & .99 \\
\hline Health effort & - & - & - & $.080 * *$ & .030 & 1.08 & $.071 *$ & .030 & 1.08 \\
\hline Religiosity & - & - & - & -.024 & .044 & .98 & -.023 & .044 & .98 \\
\hline Spirituality & - & - & - & $.305 * * *$ & .046 & 1.36 & $.302 * * *$ & .047 & 1.35 \\
\hline Openness & - & - & - & -.052 & .109 & .95 & -.060 & .110 & .94 \\
\hline Traditional service use & \multirow{2}{*}{\multicolumn{3}{|c|}{1672}} & \multirow{2}{*}{\multicolumn{3}{|c|}{1672}} & $.143^{* * *}$ & .042 & 1.15 \\
\hline$n$ & & & & & & & \multicolumn{3}{|c|}{1672} \\
\hline df & \multicolumn{3}{|c|}{15} & \multicolumn{3}{|c|}{20} & \multicolumn{3}{|c|}{21} \\
\hline Chi-square & \multicolumn{3}{|c|}{190.74} & \multicolumn{3}{|c|}{266.85} & \multicolumn{3}{|c|}{278.50} \\
\hline
\end{tabular}

$* p<.05 ; * * p<.01 ; * * * p<.001$.

IADLs $=$ instrumental activities of daily living; BADLs $=$ basic activities of daily living. 
not generally cover CAM, and having or not having insurance does not appear to influence its use. Perceived financial status does not shape the use of CAM, nor does income. Education may be picking up this enabling aspect of socioeconomic status effects: the odds of CAM use increase monotonically with higher education, from almost twice the odds for a high school diploma to over three and a half times the odds for a college degree or more, as compared to the reference category. But the odds of CAM use does not significantly decline with lower income. It is possible that people shift to CAM practices that require less income when necessary (use nonsupervised or group versus practitioner-based services).

Model 2 adds the health belief indicators. ${ }^{11}$ The addition of the group significantly improves model fit, and with the exception that age becomes significant and is inversely associated with CAM use, does not substantively alter the effects of the variables in the first model. In support of the first hypothesis, spirituality is positively associated with CAM use but, against expectations (Hypothesis 2), religiosity is not significant. Findings also partially support Hypothesis 3: health effort boosts the odds of CAM use, but health control does not. Thus high control is not only inversely associated with conventional care use, but does not predispose to CAM service use. Against expectations (Hypotheses 4 and 6, respectively), openness and social support do not predict CAM use.

CAM has frequently been found to be an "add-on" in health care use and the final model in the table tests this by using an indicator of conventional service use. Consistent with Hypothesis 5, a unit increase in (logged) conventional visits is associated with a 15 percent increase in the odds of CAM use (calculated as the difference between the odds ratio and 1, multiplied by 100).

Table 4 presents the results of second stage, generalized least squares (GLS) regressions of the number of CAM techniques used in the previous 12 months on the same sets of variables, for those with "Any CAM use." The first model shows that highly educated individuals (some college or more, relative to non-high school graduates) use more types of CAM therapies. Individuals with more chronic conditions use more nonconventional treatments. However, health insurance significantly reduces the variety of CAM services used, suggesting that a trade-off or substitution may take place with regard to the larger mix of conventional and nonconventional care. Surprisingly, the presence of intimate social support (a marital or cohabiting partner) also reduces CAM use, a finding opposite of that expected (Hypothesis 6). Thus, partners and health insurance apparently steer CAM users away from a wider variety of alternative treatments, net of other effects.

The addition of the health belief variables (Model 2) significantly improves model fit to the data, tripling the adjusted R-square from about 5 percent to about 16 percent. Consistent with the first two hypotheses, selfrated religiosity significantly decreases and self-rated spirituality significantly 
Table 4

Generalized Least Squares (GLS) Regressions

Number of complementary and alternative medicine (CAM) reported if any alternative treatments used

\begin{tabular}{|c|c|c|c|c|c|}
\hline \multicolumn{2}{|c|}{ Model 1} & \multicolumn{2}{|c|}{ Model 2} & \multicolumn{2}{|c|}{ Model 3} \\
\hline$b$ & S.E. & $b$ & S.E. & $b$ & S.E. \\
\hline $80 * *$ & .700 & -.920 & .831 & -.896 & .832 \\
\hline
\end{tabular}

Intercept

Age (years)

.001

Female

.242

White

.212

High school diploma

.310

Some college

$.506 *$

$.862 * * *$

008

$-.005$

$.241 *$

.008

.006

$.230 *$

008

College degree or more

Marital/cohabiting union

$-.462 * *$

.243

.278

.247

.295

.119

.253

.260

.256

.247

Enabling factors

Income

.004

.257

.283

.257

.261

$.622 *$

.273

.284

.258

Perceived finances

Health insurance

Usual source of care

.027

$-.605^{*}$

.278

$-.307 *$

.135

$.622 *$

.274

.134

$-.342$

.011

.007

.010

.007

.010

.018

.029

.020

.029

.030

$-.427$

.285

$-.448$

.284

.198

$-.248$

.178

$-.271$ 
Need factors

Number of chronic conditions

IADLs

$.133 * * \quad .050$

$-.196$

.117

$.128^{* *}$

.048

$.117 * *$

.047

BADLs

.333

$-.103$

.110

.122

.113

Health status 10 years earlier

$-.009$

.035

.329

$.337 *$

.172

Health beliefs and individual factors

Control over health

Health effort

-

$-.046$

Religiosity

Spirituality

- $\quad-$

$-.046$

.036

.014

.036

Openness

$-$

$.125 * * * \quad .032$

$-.044$

$.122 * * *$

$-.251 * * *$

$-.251 * * *$

$.372 * * *$

$.472 * * *$

.047

.035

.031

$.372 * * * \quad .054$

Traditional service use

$n$

df

Adjusted $R$-square

920

16

.049

Note: Standard errors (S.E.) adjusted by White's method.

$* p<.05 ; * * p<.01 ; * * * p<.001$.

IADL $=$ instrumental activities of daily living; BADL $=$ basic activities of daily living. 
increases the number of CAM techniques used. With regard to the health control variables, level of health control does not predict the number of CAM techniques used (much as it also did not predict the use of CAM), but greater health effort and openness promote a wider experience across CAM techniques for users. One change that occurs with the addition of the group of variables is that the education (SES) effect becomes a threshold effect: having a baccalaureate or higher degree is significantly associated with using more types of CAM. Another important change is that when health belief and sacred worldview orientations are accounted for, women use more types of CAM than men.

Model 3 adds the indicator for conventional service use; although conventional care is associated with a greater likelihood of CAM use (Table 3), it is not significantly associated with the number of CAM techniques used. Also, the addition of the variable does not change findings with regard to the other coefficients in Models 1 and 2. Findings are further discussed below.

\section{Discussion}

This study explores the use of CAM in the context of the use of conventional medical services. Recent studies suggest that the traditional predisposing, enabling, and need factors that are known to be associated with conventional service utilization, encourage CAM use as well, and do not clearly differentiate CAM users from nonusers. We therefore apply Andersen's extended model (1995) to a national data set newly used for this purpose, focusing on the alternative worldviews and other personal predisposing factors that have been proposed to play a role in CAM use (Ruggie 2004).

Our main findings are as follows. First, each domain of health beliefs, including self-rated religiosity and spirituality, appears to represent a different phenomenon. Higher self-rated spirituality is associated with a greater probability of CAM use and the use of more techniques. Although higher self-rated religiosity does not distinguish CAM users from nonusers, it is associated with adopting significantly fewer techniques. Assuming that the religious versus spiritual worldviews are differentiated by religious individuals' greater embeddedness in community and institutional "orthodoxies" (e.g., adherence to a set of prescribed beliefs), a religious worldview appears to carry over to constrain the use of nonconventional practices and providers. It may also be that CAM's tendency to secularize otherwise sacred techniques makes this type of care less attractive to these users (Goldstein 1999). More research is needed to examine the association and meaning of specific CAM practices in light of different religious and spiritual orientations. Neither type of worldview plays a direct role in conventional service use.

Openness shows itself to be a distinct dimension, one that is not associated with increased conventional care use and does not differentiate CAM users from 
nonusers, but does indicate those who use more versus fewer types of treatments. Also, as expected, each of the two domains of personal responsibility for health produces a different outcome. Greater health effort appears to be associated with commitment and/or collaboration in both conventional and CAM service use. Due to the cross-sectional data structure we cannot know whether high effort persons pursue reinforcement of their efforts through practitioner contact and/or technique(s), or whether medical contact and/or the utility of technique(s) stimulate health effort. In contrast, health control is inversely associated with conventional care use and, against expectations, also is not associated with CAM use or the number of CAM techniques used. Thus a wide range of beliefs have been subsumed under the label health beliefs or alternative worldviews; each may have a very different effect on health utilization and health behavior. More research is needed, with better health belief measures than available in this database.

Understanding who uses CAM, and why, is important for conventional medical practitioners, CAM practitioners, policymakers, and academic researchers. A growing problem associated with increasing CAM use is the lack of communication between providers and patients about alternative techniques (Ruggie 2004). As many as 60 percent of CAM users do not tell their physicians about their CAM use (Astin et al. 2000; less than 40\% found by Eisenberg 1998); 54 percent of breast cancer patients who use CAM do not tell their physician (Adler and Fosket 1999). Why is this so? Some patients may believe that conventional providers will be uninterested or have a negative response to CAM experimentation; others patients may believe that CAM use is irrelevant to conventional treatment (Adler and Fosket 1999). Moreover, few studies examine whether CAM users report conventional treatment to CAM practitioners. Our findings suggest that communication with all types of providers may be more difficult for health care users than is generally recognized. For users with certain health beliefs, including spiritual or religious worldviews, CAM and even conventional service use does not take place outside of this system of belief. Disclosure of CAM use to a health provider-and perhaps conventional care use to CAM providers - will likely entail more than a simple exchange of factual information. Reducing the avoidance of medical contact in some subgroups (lower conventional care utilization, net of need) and closing patient/ provider communication gaps in others, will require mutual effort toward communication across what might be perceived as chasms of separation, not only in terms of patient and provider roles, but also ideological systems and worldviews. In addition it is not clear whether a health practitioner or CAM user who works with and accepts one nonconventional set of practices, based on health beliefs, would accept others.

It is also important for conventional and CAM practitioners, policymakers, and academic researchers to understand the use of CAM in the context of 
chronic diseases. There is an interesting "fit" of alternative medicine to the treatment of chronic diseases. Chronic diseases are now the major cause of illness, disability, and death in the United States. Lifetime prevalence of CAM use has increased steadily since the 1950s, implicating a cohort effect of post-baby boomers using more alternative services (Kessler et al. 2001); about half of boomers used at least one CAM in 1997 (NCCAM 2000). Fifty percent of CAM users indicate they use CAM for the prevention of (generally chronic) illness and enhanced wellness. Others use CAM to treat symptomatic chronic conditions including diabetes, musculoskeletal conditions, emotional needs, digestive problems, and headaches (Kelner and Wellman 1997). Medical practitioners believe these diseases are caused by potentially understandable mechanisms, rooted in biology, and so believe them to be best treated by standardizing practice, even though chronic diseases have multiple, often socially rooted causes, making a "cure" difficult (Fries 1983). In contrast, CAM practitioners and techniques invoke practices of self-transformation, and so promote the "seeking" of spiritual identity as opposed to the "dwelling" and liturgy of conventional practice. The number of chronic conditions is associated with increased conventional and CAM use in this study, yet, net of this, health beliefs differentiate users versus nonusers and the types of services used. Thus even as chronic disease prevalence rises in an aging population these very different faces of health care appear to differentially attract careseekers. We can expect that future streams of afflicted individuals will turn to different types of treatment possibilities, based on differing health beliefs, and the use of some services will become more prevalent than others.

In conclusion, CAM use is widespread and growing; about half of this national sample has used at least one or more alternative technique, with spirituality, openness, and perhaps ideologically-based health efforts increasing the number of techniques used. Young- to middle-aged adults use CAM at higher rates than elderly adults; because early-life use is significantly associated with later-life use (Kessler et al. 2001), the national utilization of CAM can be expected to increase well into the foreseeable future. This ongoing evolution of health practice in modern society can be viewed in terms of first, trends of secularization and medicalization - with health and illness already having passed from being functions of religious orthodoxy (and sin), to medical materialist orthodoxy (and bodily sickness) (Goldstein 1999; Turner 1996). Now we may be witnessing the demedicalization - and further secularization - of health care as characterized by "naturopathic" and holistic practices, perhaps no less orthodox in some ways, but less determined by the previous orthodoxies. To the degree that this is occurring, however, it must be understood as a reflexive process. As individuals' adoption of CAM is shaped by alternative health beliefs and worldviews, so their greater use of such techniques and their reports of effectiveness 
may lead to even greater acceptance and use of CAM-because of physician recommendations or as part of conventional medical practice, the definitions of health, wellness, and disease change, further expanding CAM use. CAM requires further study, if for no other reason than it is likely to influence how we come to define and conceptualize health, disease, wellness, and treatment.

\section{ENDNOTES}

* The authors made equal contributions to this study. We thank the reviewers and Dr. Baffour Takyi and Dr. Brian Pendleton for their comments on previous versions. Direct correspondence to Cheryl Elman, Department of Sociology, The University of Akron, Akron, OH 44325-1905, e-mail: chery12@uakron.edu, phone: 330-972-6894, fax: 330-972-5377. Kristen Hildreth can be reached at Medina County Health Department, 4800 Ledgewood Drive, Medina, OH 44256, e-mail: khildreth@medinahealth.org.

${ }^{1} \mathrm{CAM}$, or complementary and alternative medicine, has been defined as "diverse medical and health care systems, practices, and products that are not presently considered to be part of conventional medicine" although "other terms ... include unconventional, nonconventional, unproven, and irregular medicine or health care" (NCCAM 2002). CAM use is growing, although point estimates of use vary widely across U.S. studies. One set of nationally representative studies finds that CAM utilization grew from 33.8 percent of respondents in 1990 to 42.1 percent in 1997 (Eisenberg et al. 1998). Other representative studies find use at 28.9 percent (The 1999 National Health Interview Survey, Ni et al. 2002); 48.5 percent (Bair et al. 2002, California sample of women); 50 percent (Michigan, Rafferty et al. 2002) and 62 percent when healing by prayer was included, 36 percent when excluded (The 2002 National Health Interview Survey, Barnes et al. 2004). Point estimate variation reflects different ways of defining alternative health care practices (Ernst 2000) and sampling protocols (i.e., excluding non-English-speaking respondents or other restrictions). For example, studies measure as few as one or two to as many as 27 types of CAM (Barnes et al. 2004).

${ }^{2}$ Ernst's (World Health Organization [WHO] 2000) survey of four international journal article databases (MEDLINE, EMBASE, Cochrane Library, and CISCOM) found that only 12 of 100 studies published before 1998 used nationally representative databases; only 4 of the 12 were U.S. studies. Most studies in the database used convenience samples of alternative practitioner clients, often without comparative samples of conventional care users (see Furnham and Vincent 2003; Sirois and Gick 2002 for critiques). Also, it is not clear whether studies that draw samples from supervised or practitioner-based CAM users only, fairly represent CAM users more generally (Eisenberg et al. 1998; Kelner and Wellman 1997). In sum, it is problematic to make inferences about CAM users in the United States on the basis of international studies, both because of study design issues and because one should not assume that the national health care systems and individual factors that predispose or enable health care are similar (Ruggie 2004).

${ }^{3}$ Most representative social science databases do not contain information about CAM use. The representative health studies that report CAM use have limited (if any) information about respondents' detailed health beliefs, especially religious or spiritual orientations. Two recent nationally representative studies conducted in the United States find a strong association between health control, spiritual beliefs, and CAM use (Astin 1998; Sutherland et al. 2003 Gallup poll data).

${ }^{4}$ After reviewing cross-national studies, Ruggie concludes that U.K. respondents' (with more universal access to care) tend to voice dissatisfaction with specific care providers, but U.S. respondents tend to like their practitioners and have more global discontents about conventional medicine 
(2004:49), due to poor treatment response, more serious illness, or more unmet health needs despite treatment (McGregor and Peay 1996 have similar findings for Australia). This may also reflect different mixes of alternative worldviews and health beliefs and expectations for healing (Goldstein 1999).

${ }^{5}$ Theory has yet to detail how both of these phenomena arise and overlap (MacDonald 2000). Empirical work shows that: (1) survey respondents consistently differentiate the "religious" from the "spiritual," when evaluating definitions and hypothetical profiles; (2) respondents' criteria for differentiation is "organized and coherent" (see overview of research in Zinnbauer et al. 1999), although classes of subjects, such as students, clinical, or pastoral workers, may have characteristically divergent views; and (3) self-rated differences matter, for predicting individual health and well-being (Wink and Dillon 2003). There is not yet a crisp distinction between religiosity and spirituality and both concepts have been poorly operationalized in studies about health (George et al. 2000; MacDonald 2000; Zinnbauer et al. 1999). A recent literature review identifies 70 separate scales and constructs that have been used to operationalize spirituality in a nonsystematic (a-theoretical) way, making comparisons difficult (MacDonald 2000).

${ }^{6}$ It is usually midlife when personal autonomy, self-reflection about mortality, and social context and responsibility call into play the human development associated with spirituality. In one key study critical factors include cognitive orientation (meaning/purpose in life), existential well-being, a phenomenological dimension (involving mystical or peak experiences), paranormal beliefs, and a more general religiousness (MacDonald 2000).

${ }^{7}$ The National Institutes of Health (NIH) categorizes CAM into five domains: (1) Alternative Medical Systems such as homeopathy and acupuncture; (2) Mind-Body Interaction techniques such as biofeedback and hypnosis; (3) Biologically-Based treatments such as vitamins and diets; (4) Manipulative and Body-Based methods such as chiropractic and massage therapy; and (5) Energy Therapies such as energy healing and spiritual healing by others (NCCAM 2000) This study includes one or more therapies in each domain.

${ }^{8}$ Unfortunately, the survey instrument did not present specific definitions of religion or spirituality to respondents. Respondents self-rated their level of religiosity and spirituality, and the relative importance of both, but were not provided clear definitions of terms.

${ }^{9}$ The variable is a composite of several questions asking if the respondent was covered by the following: Private insurance directly from the insurer; Private insurance through current or former employer; Private insurance through spouse's current or former employer; Private insurance through own union; Private insurance through spouse's union; Medicare; Medicaid, or other government program; CHAMPUS, CHAMPVA, or other veterans program; insurance to cover mental health visits.

${ }^{10} \mathrm{~A}$ model that excludes the need variables finds income not associated with CAM use.

${ }^{11}$ Thirty percent of the sample, unweighted (696 persons) report use of one (and only one) type of CAM. Of users of a single type of CAM, one person uses spiritual healing, and 115 use spiritual practices. Models 2 and 3 in Tables 3 and 4 were rerun after deleting the spiritual healing and spiritual practices categories of CAM from the dependent variables. Deleting these two categories does not change results; all coefficients retain signs and significance.

\section{REFERENCES}

Adler, S. R. and J. Fosket. 1999. "Disclosing Complementary and Alternative Medicine Use in the Medical Encounter: A Qualitative Study in Women with Breast Cancer." Journal of Family Practice 48(6):453-8. 
Andersen, Ronald, Joanna Kravis, and Odin W. Andersen. 1975. Equity in Health Services. Cambridge, MA: Ballinger Publishing.

Andersen, Ronald M. 1995. "Revisiting the Behavioral Model and Access to Medical Care: Does It Matter?" Journal of Health and Social Behavior 36(March):1-10.

Astin, John A. 1998. "Why Patients Use Alternative Medicine." Journal of the American Medical Association 279(19):1548-53.

Astin, John A., Kenneth R. Pelletier, Ariane Marie, and William L. Haskell. 2000. "Complementary and Alternative Medicine Use among Elderly Persons: One-Year Analysis of a Blue Shield Medicare Supplement." Journal of Gerontology 55A:M4-M9.

Bair, Yall A., Ellen B. Gold, Gail A. Greendale, Barbara Sternfeld, Shelley R. Adler, Rahman Azari, and Martha Harkey. 2002. "Ethnic Differences in Use of Complementary and Alternative Medicine at Midlife: Longitudinal Results from SWAN Participants." American Journal of Public Health 92(11):1832-40.

Barnes, Patricia M., Eve Powell-Griner, Kim McFann, and Richard L. Nahin. 2004. "Complementary and Alternative Medicine Use among Adults: United States 2002.” Advance Data, No. 343. Center for Disease Control, U.S. Dept. of Health and Human Services. Hyattsville, MD: National Center for Health Statistics.

Berstein, Judith H. and Judith T. Shuval. 1997. "Non-Conventional Medicine in Israel: Consultation Patterns of the Israeli Population and Attitudes of Primary Care Physicians." Social Science and Medicine 44(9):1341-8.

Brim, Orville G., Paul B. Baltes, Larry L. Bumpass, Paul D. Cleary, David L. Featherman, William R. Hazzard, Ronald C. Kessler, Margie E. Lachman, Hazel Rose Markus, Michael G. Marmot, Alice S. Rossi, Carol D. Ryff, and Richard A. Shweder. 1996. National Survey of Midlife Development in the United States (MIDUS), 1995-1996 [Computer file]. $2^{\text {nd }}$ ICPSR version. Ann Arbor, MI: DataStat, Inc./Boston: Harvard Medical School, Department of Health Care Policy.

Caspi, Opher, Mary Koithan, and Michael W. Criddle. 2004. "Alternative Medicine or "Alternative' Patients: A Qualitative Study of Patient-Oriented Decision-Making Processes with Respect to Complementary and Alterative Medicine." Medical Decision Making 24:6479.

Cherniack, E. Paul, Richard S. Senzel, and Cynthia X. Pan. 2001. "Correlates of Use of Alternative Medicine by the Elderly in an Urban Population." The Journal of Alternative and Complementary Medicine 7(3):227-80.

Chatters, Linda M. 2000. "Religion and Health: Public Health Research and Practice." Annual Reviews of Public Health 21: 335-67.

Dull, Valerie T. and Laurie A. Skokan. 1995. "A Cognitive Model of Religion's Influence on Health.” Journal of Social Issues 51(2):49-64.

Druss, Benjamin G. and Robert A. Rosenheck. 1999. "Association between Use of Unconventional Therapies and Conventional Medical Services." Journal of the American Medical Association 282(7):651-6.

Eisenberg, David M., Roger B. Davis, Susan L. Etter, Scott Appel, Sonja Wilkey, Maria Van Rompay, and Ronald Kessler. 1998. "Trend Is Alternative Medicine Use in the United States, 1990-1997." Journal of the American Medical Association 280:1569-75.

Ernst, E. 2000. "Prevalence of Use of Complementary/Alternative Medicine: A Systematic Review." Bulletin of the World Health Organization 78(2):252-7.

Fries, James F. 1983. "The Compression of Morbidity." Health and Society 61(3):397-419.

Furnham, Adrian and Rachel Beard. 1995. "Health, Just World Beliefs and Coping Style Preferences in Patients of Complementary and Orthodox Medicine." Social Science and Medicine 40:1425-32. 
Furnham, Adrian and Charles A. Vincent. 2003. "Reasons for Using CAM.” Pp. 61-78 in Complementary and Alternative Medicine, edited by Merrijoy Kelner, Beverly Wellman, Bernice Pescosolido, and Mike Saks. New York: Routledge.

Gelberg, Lillian, Teresa C. Gallagher, Ronald M. Andersen, and Paul Koegel. 1997. "Competing Priorities as a Barrier to Medical Care among Homeless Adults in Los Angeles." American Journal of Public Health 87(2):217-20.

George, Linda, David Larson, Harold G. Koenig, and Michael E. McCullouch. 2000. "Spirituality and Health: What We Know, What We Need to Know." Journal of Social and Clinical Psychology 10(1):102-16.

Goldstein, Michael S. 1999. Alternative Health Care Medicine, Miracle, or Mirage? Philadelphia, PA: Temple University Press.

Green, Carla A. and Clyde R. Pope. 1999. "Gender, Psychosocial Factors and the Use of Medical Services: A Longitudinal Analysis." Social Science and Medicine 48:1363-72.

Kelner, Merrijoy and Beverly Wellman. 1997. "Health Care and Consumer Choices: Medical and Alternative Therapies." Social Science and Medicine 45:203-12.

Kessler, Ronald C., Roger B. Davis, David F. Foster, Maria I. Van Rompay, Ellen Walters, Sonja A. Wilkey, Ted J. Kaptchuk, and David M. Eisenberg. 2001. "Long-Term Trends in the Use of Complementary and Alternative Medical Therapies in the United States." Annals of Internal Medicine 135(4):262-8.

Kitigawa, E. and P. Hauser 1973. Differential Mortality in the U.S.: A Study in Socioeconomic Epidemiology. Cambridge, MA: Harvard University Press.

Levin, Jeffrey S. and Linda M. Chatters. 1998. "Religion, Health, and Psychosocial Well-Being in Older Adults." Journal of Aging and Health 10(4):504-31.

MacDonald, Douglas A. 2000. "Spirituality: Description, Measurement and Relation to the Five Factor Model of Personality." Journal of Personality 68:153-97.

McFadden, Susan H. 1996. "Religion, Spirituality, and Aging." Pp. 162-7 in Handbook of the Psychology of Aging, 4th ed., edited by James Birren and K. W. Schaie. San Diego, CA: Academic Press.

McFarland, Bentson, Douglas Bigelow, Brigid Zani, Jason Newsom, and Mark Kaplan. 2002. "Complementary and Alternative Medicine Use in Canada and the United States." American Journal of Public Health 92(10):1616-18.

McGregor, Katherine J. and Edmund R. Peay. 1996. "The Choice of Alternative Therapy for Health Care: Testing Some Propositions.” Social Science and Medicine 43(9):1317-27.

National Center for Complementary and Alternative Medicine (NCCAM). "Expanding Horizons of Healthcare: Five Year Strategic Plan, 2001-2005.” National Center for Complementary and Alternative Medicine Strategic Plan 2000. Pub. No. 01-5001. Retrieved June 22, 2005. $<$ http://www.nccam.nih.gov/health/whatiscam>.

- "What Is Complementary and Alternative Medicine?" National Center for Complementary and Alternative Medicine Strategic Plan 2002. Pub. No. D156. Retrieved June 22, 2005. $<$ http://www.nccam.nih.gov/health/whatiscam>.

Ni, Hanyu, Catherine Simile, and Ann M. Hardy. 2002. "Utilization of Complementary and Alternative Medicine by United States Adults." Medical Care 40(4):353-8.

Noelker, Linda S., Amasa B. Ford, Atwood D. Gaines, Maire R. Haug, Paul K. Jones, Kurt C. Stange, and Zak Mefrouche. 1998. "Attitudinal Influences on the Elderly's Use of Assistance." Research on Aging 20(3):317-38.

Pawluch D., R. Cain, and J. Gillett. 1994. "Ideology and Alternative Therapy Use among People Living with HIV/AIDS." Health and Canadian Society 2(1):63-84.

Poloma, Margaret M. and Brian Pendleton. 1989. "Exploring Types of Prayer and Quality of Life: A Research Note." Review of Religious Research 31(1):46-53. 
1990. "Religious Domains and General Well-Being." Social Indicators Research 22:255-76.

Rafferty, Ann P., Harry B. McGee, Corinne E. Miller, and Michele Reyes. 2002. "Prevalence of Complementary and Alternative Medicine Use: State-Specific Estimates from the 2001 Behavioral Risk Factor Surveillance System." American Journal of Public Health 92(10):1598-1600.

Rew, Lynn. 1998. "Access to Health Care for Latina Adolescents." Journal of Adolescent Health 23:194-204.

Ross, Catherine and Chia-Ling Wu. 1995. "The Links between Education and Health." American Sociological Review. 60:719-45.

Ruggie, Mary. 2004. Marginal to Mainstream: Alternative Medicine in America. New York: Cambridge University Press.

Sharma, Ursula. 1992. Complementary Medicine Today: Practitioners and Patients. London: Routledge.

Sirois, Fuschia M. and Mary L. Gick. 2002. "An Investigation of the Health Beliefs and Motivations of Complementary Medicine Clients." Social Science and Medicine 55(2002):1025-37.

Sutherland, Jean Anne, Margaret M. Poloma, and Brian F. Pendleton. 2003. "Religion, Spirituality, and Alternative Health Practices: The Baby Boomers and Cold War Cohorts." Journal of Religion and Health 42:315-38.

Turner, Bryan. 1996. The Body and Society. London: Sage Publications.

Wellman, Beverly. 2003. "Partners in Illness: Who Helps When You Are Sick?" Pp. 61-78 in Complementary and Alternative Medicine, edited by Merrijoy Kelner, Beverly Wellman, Bernice Pescosolido, and Mike Saks. New York: Routledge.

White, Halbert. 1980. "A Heteroscedasticity Consistent Covariance Matrix and a Direct Test for Heteroscedasticity." Econometrica 48:817-38.

Williams, Allison. 1998. "Therapeutic Landscapes in Holistic Medicine." Social Science and Medicine 46(9):1193-203.

Wink, Paul and Michelle Dillon. 2003. "Religiousness, Spirituality and Psychosocial Functioning in Late Adulthood: Findings from a Longitudinal Study." Psychology and Aging 18:916-24.

Wolsko, Peter M., David M. Eisenberg, Roger B. Davis, Susan L. Ettner, and Russell S. Phillips. 2002. "Insurance Coverage, Medical Conditions, and Visits to Alternative Health Providers." Archives of Internal Medicine 162:281-7.

Wolsko, Peter, Lindsay Ware, Jean Kutner, Chen-Tan Lin, Gail Albertson, Lisa Cyran, Lisa Schilling, and Robert J. Anderson. 2000. "Alternative/Complementary Medicine: Wider Usage than Generally Appreciated." Journal of Alternative and Complementary Medicine 6:321-6.

Wuthnow, Robert. 1998. After Heaven: Spirituality in America Since the 1950s. Berkeley: University of California Press.

Wray, Linda, A. Regula Herzog, Robert Willis, and Robert Wallace. 1998. "Education and Health." Journal of Health and Social Behavior 39:271-94.

Zinnbauer, Brian J., Kenneth L. Pargament, and Allie B. Scott. 1999. "The Emerging Meanings of Religiosity and Spirituality: Problems and Prospects." Journal of Personality 67:899-919. 